\title{
INVESTIGATION OF NATURAL CONVECTION CHARACTERISTICS WITH BROWNIAN MOTION EFFECT USING DIFFERENT NANOFLUIDS
}

\author{
Saleh Etaig, ${ }^{1, *}$ Reaz Hasan, $^{2}$ \& Noel Perera ${ }^{2}$

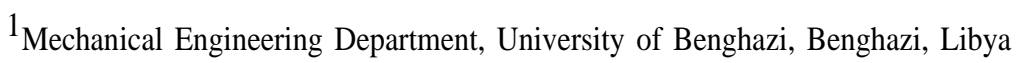 \\ ${ }^{2}$ Mechanical and Construction Engineering Department, Northumbria University, \\ Newcastle, United Kingdom
}

*Address all correspondence to: Saleh Etaig, Mechanical Engineering Department, University of Benghazi, Benghazi, Libya, E-mail: Salehorafi@yahoo.com

\begin{abstract}
This paper reports the effect of Brownian motion on fluid flow and heat transfer performance us- ing various nanofluids in natural convection in a square enclosure. The energy and Navier-Stokes equations are solved numerically using a finite-volume approach. The effect of Brownian motion was employed based on a thermal conductivity model with a Brownian motion effect. The effect of the volume concentration on the enhancement of heat transfer was studied incorporating the Brow- nian motion. The influence of the effective thermal conductivity on the enhancement was also in- vestigated for a range of volume fraction concentrations. Various volume concentrations were tested in the present study: $2 \%, 3 \%, 4 \%$, and $6 \%$. Different Raleigh numbers were investigated for dif- ferent nanoparticles. The results revealed that an increase in the volume fraction deteriorates the heat transfer. The velocity gradients were also found to be affected by the volume fraction. The tem- perature profile for different Rayleigh numbers is presented. Three different nanofluids ( $\mathrm{Cu}$-water, TiO-water, and $\mathrm{AL}_{2} \mathrm{O}_{3}$-water) were studied.
\end{abstract}

KEY WORDS: heat transfer, computational fluid dynamics (CFD), natural convection, Brownian motion

\section{INTRODUCTION}

Natural convection heat transfer arises within an enclosure due to the temperature difference and buoyancy force. One of the factors limiting the enhancement of natural convection heat transfer is the intrinsically low thermal conductivity of conventional fluids.

Nanofluids are suspensions with less than $100 \mathrm{~nm}$ diameter. The material in the suspension can be metalic or non-metallic. The pioneering work that introduced this new class fluids was first done by Choi and Eastman (1995), who coined the term nanofluid. Nanofluids are dilute suspensions of fluids. Nanofluids have been found to retain enhanced thermophysical properties of a fluid. These properties are the following: thermal conductivity, viscosity, density, and heat capacity. Furthermore, the convective heat transfer coefficient was found to increase in comparison to base fluids like oil or water. Nanofluids have demonstrated feasible applicability in many fields such as in electronic applications, industrial cooling systems, heating buildings, nuclear cooling systems, and many other applications. 


\begin{tabular}{|c|c|c|}
\hline \multicolumn{3}{|c|}{ NOMENCLATURE } \\
\hline$A$ & area $\left(m^{2}\right)$ & $\mathrm{Q}^{11}$ heat flux $\left(\mathrm{W} / \mathrm{m}^{2} \cdot \mathrm{K}\right)$ \\
\hline$C_{P}$ & specific heat at constant pressure & Rayleigh number \\
\hline & $\left(\mathrm{kJ} / \mathrm{kg}^{-1} \cdot \mathrm{K}^{-1}\right)$ & Reynolds number $(=U D \rho / \mu)$ \\
\hline $\begin{array}{l}C_{F} \\
D\end{array}$ & $\begin{array}{l}\text { skin friction factor } \\
\text { diameter (m) }\end{array}$ & $T \quad$ temperature $(\mathrm{K})$ \\
\hline$h$ & heat transfer coefficient & Greek Symbols \\
\hline$K$ & thermal conductivity $\left(\mathrm{W} / \mathrm{m}^{2} \cdot \mathrm{K}\right)$ & $\mu \quad$ viscosity $\left[\mathrm{kg}\left(\mathrm{m}^{-1} / \mathrm{s}^{-1}\right)\right]$ \\
\hline$L$ & length (m) & density $\left(\mathrm{kg} / \mathrm{m}^{-3}\right)$ \\
\hline $\mathrm{Nu}$ & Nusselt number $(=h D / K)$ & volume fraction \\
\hline
\end{tabular}

The investigation of the enhancement of heat transfer with the use of nanofluids has recently attracted the attention of many researchers, such as Xuan and Li (2000), Khanafer et al. (2003), and Etaig et al. (2017). Putra et al. (2003) reported that adding nanoparticles to a base fluid in the natural convective characteristics for water-based $\mathrm{Al}_{2} \mathrm{O}_{3}$ nanofluids detriorates natural convective heat transfer with an increase in the nanoparticle concentration. However, they did not give an acceptable reason for this decrease in natural convective heat transfer in a cavity with an increment of the volume fraction of nanoparticles. According to many literature investigations, thermal conductivity is found to be the most affective key role in the enhancement utilizing nanofluids, where the effective thermal conductivity was modeled using theoretical and experimental models of nanofluids. Saleh et al. (2011) investigated natural convection in a trapezoidal enclosure filled with nanofluids. Nasrin et al. (2012) investigated the heat transfer performance in a vertical closed enclosure and found that the nanoparticle volume fraction played a significant role in the temperature field. Ghasemi and Aminossadati (2009) carried out a numerical study and investigated natural convection heat transfer in an inclined enclosure filled with $\mathrm{CuO}-$ water nanofluids. Ho et al. (2010) experimentally investigated the natural convection heat transfer of an $\mathrm{Al}_{2} \mathrm{O}_{3}$-water-based nanofluid. Ghasemi and Aminossadati (2010) studied the effect of Brownian motion on a triangular enclosure with natural convection.

Manca et al. (2001) conducted an experimental investigation of air natural convection on a vertical isoflux plate with a downstream unheated extension and a facing parallel shroud. They reported improvement in the thermal performance in most of configurations of the channel. Sarris et al. (2004) presented a numerical investigation that gives a better understanding of some aspects of natural convection in a glass melting tank heated locally from below. They tested the effects of the location of a heated strip by placing it at center and off-center positions on the tank bottom wall. They highlighted that for small Rayleigh numbers, the heat transfer is dominated by conduction, while at higher Rayleigh numbers convection becomes dominant.

Aminossadati and Ghasemi (2009) numerically studied natural convection in a square enclosure filled with $\mathrm{CuO}$-water nanofluid at volume fractions up to $4 \%$. They assumed that the side and top walls were insulated. They divided the bottom wall into four sections. Based on the position of the hot and cold parts, two cases were considered. They found that an increase in the Rayleigh number promoted natural convection flows, and hence, reduced the heat source temperature.

Oztop and Abu-Nada (2008) presented numerical simulations of natural convection in a partially heated rectangular cavity filled with nanofluids. They considered the effect of different 
types of nanoparticle in a water-based fluid $\left(\mathrm{Cu}, \mathrm{Al}_{2} \mathrm{O}_{3}\right.$, and $\left.\mathrm{TiO}_{2}\right)$, as well as the volume concentration of the nanoparticles and the temperature fields. In their numerical study, a heat source with finite length was placed on the left side with a higher temperature than the right side. They reported that the level of heat transfer improved with increasing the heater size and the Rayleigh number within the range of $10^{3}$ to $5 \times 10^{5}$.

Sun and Pop (2011) studied and numerically investigated the problem of natural convection heat transfer of a right angle triangular enclosure filled with a porous medium and a nanofluid. For the enclosure, the heat source was located on the vertical wall, the inclined wall was cold with a fixed temperature, and the vertical wall was adiabatic. They tested the same three types of nanoparticles, such as $\mathrm{Cu}, \mathrm{Al}_{2} \mathrm{O}_{3}$, and $\mathrm{TiO}_{2}$, and the effect of the nanoparticle volume fraction. They studied the effect of the Rayleigh number on the porous medium, heater size, and enclosure aspect ratio. They reported that the Nusselt number had a maximum value at both the highest Rayleigh number and largest heater size. Heat transfer was enhanced within the cavity by decreasing the enclosure aspect ratio and lowering the heat source. Furthermore, the Cu-based nanofluid performed better in relation to heat transfer.

The aim of this paper is to investigate the heat transfer enhancement in natural convection in a square enclosure with different nanoparticle types, in which Brownian motion is incorporated.

\section{PROBLEM DESCRIPTION}

A schematic diagram of the physical domain is shown in Fig. 1. The model consists of a square enclosure with length and height equal to $L$ and $W$, respectively. The upper and bottom walls are thermally insulated, the left wall is heated at temperature $T_{H}$, and right wall is maintained at lower temperature $T_{C}$. The enclosure is filled with a water-based nanofluid. The nanoparticles investigated are $\mathrm{Al}_{2} \mathrm{O}_{3}, \mathrm{Cu}$, and $\mathrm{TiO}_{2}$, with a spherical diameter of $25 \mathrm{~nm}$. The water and the nanoparticles are assumed to be in thermal equilibrium, Newtonian, and incompressible. The flow is laminar. The thermophysical properties are assumed to be temperature dependent, which are given in the following section. The thermophysical properties of the $\mathrm{Al}_{2} \mathrm{O}_{3}, \mathrm{Cu}$, and $\mathrm{TiO}_{2}$ particles are given in Table 1.

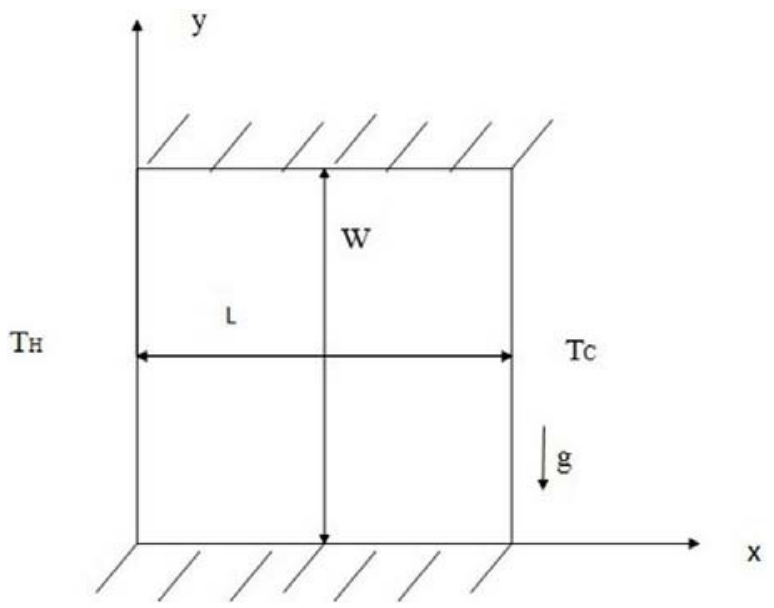

FIG. 1: Problem geometry 
TABLE 1: Nanoparticle thermophysical properties

\begin{tabular}{|c|c|c|c|}
\hline Nanoparticle & Density $\left(\mathbf{k g} / \mathbf{m}^{\mathbf{3}}\right)$ & $\begin{array}{c}\text { Thermal Conductivity } \\
\left(\mathbf{W} / \mathbf{m}^{-1} \cdot \mathbf{K}^{-\mathbf{1}}\right)\end{array}$ & $\begin{array}{c}\text { Specific Heat } \\
\left(\mathbf{J} / \mathbf{k g}^{-\mathbf{1}} \cdot \mathbf{K}^{-1}\right)\end{array}$ \\
\hline $\mathrm{Al}_{2} \mathrm{O}_{3}$ & 3950 & 35 & 765 \\
\hline $\mathrm{Cu}$ & 8933 & 400 & 385 \\
\hline $\mathrm{TiO}_{2}$ & 4250 & 8.93 & 686.2 \\
\hline
\end{tabular}

\section{GOVERNING EQUATIONS}

The governing equations solved in the present study are the continuity, momentum, and energy equations, which are written as follows:

- Continuity equation

$$
\frac{\partial \rho}{\partial t}+\nabla \cdot(\rho \mathbf{V})=0
$$

- Momentum equation

$$
\frac{\partial}{\partial t}(\rho \mathbf{V})+\nabla \cdot \rho \mathbf{V} \mathbf{V}=\rho \mathbf{f}+\nabla \cdot P_{i j}
$$

- Energy equation

$$
\frac{\partial E_{t}}{\partial t}+\nabla \cdot E_{t} \mathbf{V}=\frac{\partial Q}{\partial t}-\nabla \cdot \mathbf{q}+\rho \mathbf{f} \cdot \mathbf{V}+\nabla \cdot\left(P_{i j} \cdot \mathbf{V}\right)
$$

The thermophysical properties of the nanofluid are expressed as follows. The density is calculated as

$$
\rho_{n f}=(1-\phi) \rho_{f}+\emptyset \rho_{s}
$$

The specific heat is written as

$$
C_{p n f}=\frac{(1-\emptyset)\left(\rho C_{p}\right)_{f}+\emptyset\left(\rho C_{p}\right)_{s}}{\rho_{\text {eff }}}
$$

The thermal conductivity is modeled as

$$
K_{\text {eff }}=K_{\text {static }}+K_{\text {Brownian }}
$$

The static thermal conductivity is written as (Corcione et al., 2013)

$$
\frac{K_{\text {static }}}{K_{f}}=1+4.4 \operatorname{Re}^{0.4} \operatorname{Pr}^{0.66}\left(\frac{T}{T_{f r}}\right)^{10}\left(\frac{K_{s}}{k_{f}}\right)^{0.03} \emptyset^{0.66}
$$

The Brownian thermal conductivity is expressed as (Koo and Kleinstreuer, 2004)

$$
K_{\text {Brownian }}=5 \times 10^{4} \beta \emptyset \rho_{f} C_{p f} \sqrt{\frac{K T}{\rho_{s} d_{s}}} f(T, \emptyset)
$$

where $K_{b}$ is the Boltzmann constant $\left(=1.3807 \times 10^{-23}\right)$

$$
\beta=0.0011(100 \emptyset)^{-0.7272}
$$


The Reynolds number is calculated in $\mathrm{Eq}$. (6) as

$$
\operatorname{Re}=\frac{2 \rho K_{b} T}{\pi \mu_{f}^{2} d_{p}}
$$

where $d_{p}$ is the particle diameter, and $\operatorname{Pr}$ is the Prandtl number for the base fluid, which is written as

$$
\operatorname{Pr}=\frac{\mu C_{p}}{K}
$$

The temperature function in $\mathrm{Eq}$. (8) is given by

$$
f(T, \emptyset)=(-6.04 \emptyset+0.405) T+(1722.3 \emptyset-134.63)
$$

The viscosity in this investigation is modeled as proposed by Etaig et al. $(2016,2018)$ as

$$
\mu_{\text {static }}=\mu_{f}\left(1+5 \emptyset+80 \emptyset^{2}+160 \emptyset^{3}\right)
$$

The effective viscosity is calculated as

$$
\mu_{\text {off }}=\mu_{\text {stabc }}+\mu_{\text {Browning }}
$$

The Brownian viscosity is calculated as

$$
\mu \text { Bronzixn }=5 \times 10^{4} \beta \emptyset \rho \rho \sqrt{\frac{K T}{\rho_{s} d_{s}}} f(T, \emptyset)
$$

where $d_{f}$ and $d_{s}$ are the equivalent diameter of the base fluid and nanoparticle diameter, respectively. The equivalent diameter of the base fluid is given by

$$
d f=0.1\left(\frac{6 M}{N \pi \rho f_{0}}\right)^{1 / 3}
$$

where $M$ is the molecular mass weight of the base fluid; $N$ is the Avogadro number; and $\rho f o$ is the mass density of the base fluid calculated at $T=293 \mathrm{~K}$. The convective heat transfer coefficient is given by

$$
h=\frac{Q}{A \Delta T}
$$

where $Q$ is the heat flux, and $\Delta T$ is $T_{H}-T_{C}$

$$
\mathrm{Nu}=\frac{h L}{K_{\text {eff }}}
$$

where $L$ is the characteristic length. The Rayleigh number is defined as

$$
\mathrm{R} \mathbf{a}=\frac{g \beta L^{3} \Delta T}{\alpha v}
$$

where $\beta$ is the thermal expansion; $\alpha$ is the thermal diffusivity $\left(=K / \rho C_{p}\right)$; and $\nu$ is the kinematic viscosity $(=\mu / \rho)$. The thermophysical properties of the nanoparticles are given in Table 1 . 


\section{NUMERICAL PROCEDURE}

The computational fluid dynamics (CFD) code used in this investigation is Workbench 15 (AN- SYS, 2013). The nanofluid is modeled as a single-phase model. Equations (4), (5), (6), and (14) are used to model the density, specific heat, thermal conductivity, and viscosity, respectively. The laminar model was used in the natural convection simulation. For pressure velocity coupling, Courant number $=200$. Under the relaxation factor, 1 was chosen for the density, body force, and energy. Explicit relaxation factor $=0.75$ for the momentum and pressure, the body force was weighted for pressure spatial discretization, the time step $=0.021 \mathrm{~s}$, the number of time steps $=17,000$, the transient formulation was first-order implicit, and the hot and cold temperatures for the boundary conditions were 274 and $273 \mathrm{~K}$, respectively.

\section{GRID INDEPENDENCY STUDY}

A grid independence test was carried out in order to ensure that the solution obtained was mesh independent. The simulations were first done for various meshes with different numbers of cells and the average Nusselt number was calculated for each mesh. The results of the five meshes tested with the Nusselt number are given in Table 2. It can be seen that the Nusselt number for mesh 4 with 10,700 cells was found to remain unchanged, and hence, mesh 4 was selected for the present numerical simulations.

\section{VALIDATION OF RESULTS}

The present CFD code results for the average Nusselt number and various Rayleigh numbers along the hot wall were validated with the results available in the literature for natural convection in an enclosure filled with nanofluids, as presented in Table 3. The present code was further validated against the numerical simulation of Khanafer et al. (2003), as shown in Fig. 2. It can be clearly seen that the present code is in excellent agreement with the published literature results.

TABLE 2: Mesh dependency test results

\begin{tabular}{|c|c|c|}
\hline Mesh & Number of Cells & Nu \\
\hline Mesh 1 & 6400 & 1.864 \\
\hline Mesh 2 & 8400 & 2.013 \\
\hline Mesh 3 & 10,200 & 2.212 \\
\hline Mesh 4 & 10,700 & 2.323 \\
\hline Mesh 5 & 11,200 & 2.324 \\
\hline
\end{tabular}

TABLE 3: Validation of the results

\begin{tabular}{|c|c|c|c|c|}
\hline \multirow[t]{2}{*}{$\mathrm{Nu}$} & \multicolumn{2}{|c|}{ Cu-Water $(\varphi=5 \%)$} & \multicolumn{2}{|c|}{$\mathrm{Al}_{2} \mathrm{O}_{3}-$ water $(\varphi=2 \%)$} \\
\hline & Present Study & $\begin{array}{l}\text { Kahveci (Kahveci } \\
\text { and Öztuna, 2009) }\end{array}$ & Present Study & Ho et al. (2010) \\
\hline $\mathrm{Ra}=10^{4}$ & 2.431 & 2.461 & 2.323 & 2.372 \\
\hline $\mathrm{Ra}=10^{5}$ & 5.072 & 5.136 & 4.769 & 4.700 \\
\hline $\mathrm{Ra}=10^{6}$ & 9.946 & 10.04 & 9.389 & 9.314 \\
\hline
\end{tabular}




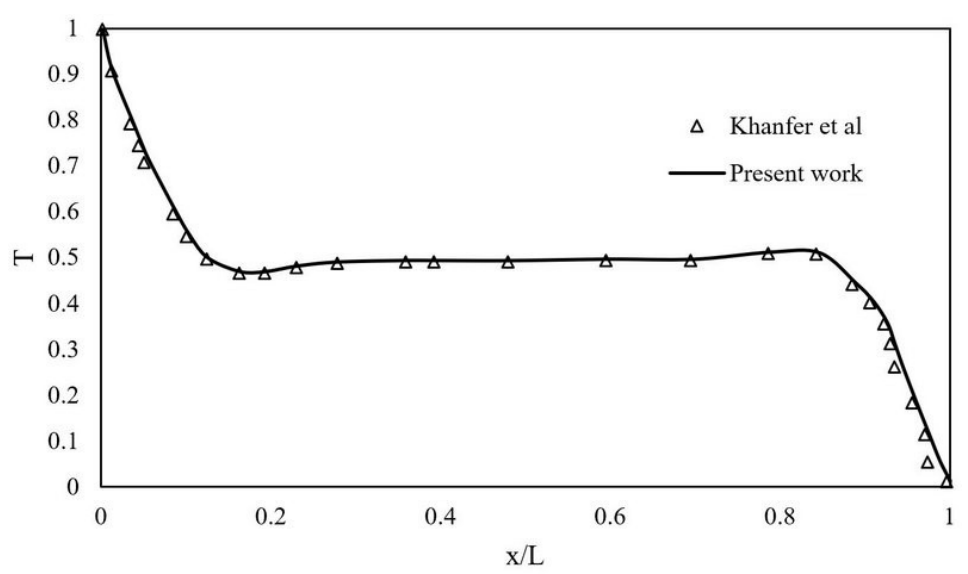

FIG. 2: Validation of the results

\section{RESULTS AND DISCUSSION}

The effect of the volume fraction on the heat transfer rate was investigated for a range of Rayleigh numbers. Four Rayleigh numbers were tested in the present study: $\mathrm{Ra}=1 \times 10^{4}, 1 \times 10^{5}$, $1 \times 10^{6}$, and $1 \times 10^{7}$. The volume fractions tested were between $2 \%$ and $6 \%$. The Nusselt number was calculated based on two scenarios. In the first scenario, Brownian motion was taken into account; in the second scenario, the effect of Brownian motion was not considered. The results for these investigations are given in Fig. 3, which shows the variations of Nusselt number (the $Y$-axis) against the volume fraction $\varphi$ (the $X$-axis). As shown in Fig. 3, for all Rayleigh numbers, the Nusselt number decreases as the volume fraction decreases. This agrees well with many previously published results reported in the literature. This decrease is not in favor of heat transfer convection since the increase in the Nusselt number is an indication of the heat transfer enhancement. This deterioration in the heat transfer is clearer at higher Rayleigh numbers. This decline is less significant in Rayleigh numbers $1 \times 10^{4}$ and $1 \times 10^{5}$. However, the increase in

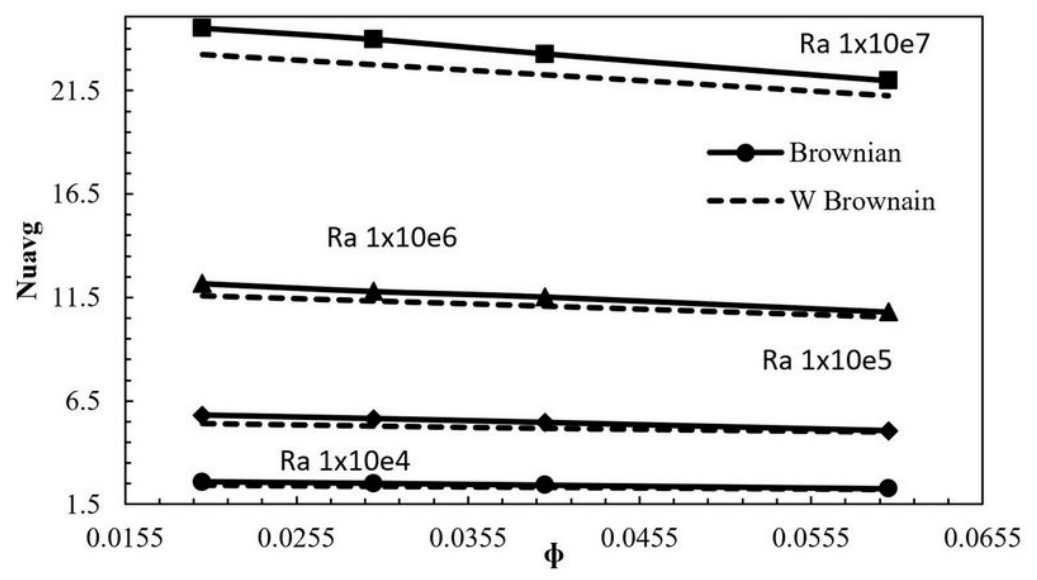

FIG. 3: Change of Nusselt number versus volume fraction 
the Rayleigh number led to an increase in the Nusselt number. As shown in Fig. 3, Ra $=1 \times 10^{7}$ showed the highest Nusselt number and subsequently the highest heat transfer rate, while $\mathrm{Ra}=$ $1 \times 10^{4}$ had the lowest Nusselt number.

The effect of Brownian motion was also investigated and the results are shown in Fig. 3. The Nusselt number calculated with Brownian motion is higher, which is due to an increase in thethermal conductivity as a result of the Brownian effect. This is attributed to the increase in ther- mal conductivity in Eq. (7), since it is well established that an increase in thermal conductivity results in an increase in the Nusselt number. This increase is obvious in Fig. 3 for Rayleigh numbers $1 \times 10^{6}$ and $1 \times 10^{7}$, where higher Rayleigh numbers are accompanied by higher velocities in the near-wall region; these higher velocities promote the heat transfer rate. Figure 3 shows that the effect of the volume fraction on the Nusselt number is noticeable at higher Rayleigh numbers than at lower Rayleigh numbers. This is associated with the conductiondominated mechanism for heat transfer at lower Rayleigh numbers compared to the convection mechanism at higher Rayleigh numbers. The buoyancy force increases and exceeds the viscous forces, and hence, heat transfer is dominated by convection at high Rayleigh numbers.

In order to gain better understanding of the effect of nanoparticles on the heat performance, variations of the Nusselt and Rayleigh numbers for various nanoparticles was investigated and the results are depicted in Fig. 4. The investigations were done for three nanofluids with waterbased fluid and three different nanoparticles, $\mathrm{Cu}, \mathrm{TiO}_{2}$, and $\mathrm{Al}_{2} \mathrm{O}_{3}$. The results are shown for a constant volume fraction $(2 \%)$ and aspect ratio $=1$.

The Nusselt number was found to increase with an increase in the Rayleigh number for all nanoparticles tested. The difference between the nanoparticles is presented for the thermophysical properties shown in Table 1 . All nanofluids showed similar results; however, the $\mathrm{Al}_{2} \mathrm{O}_{3}$-water nanofluid presented $2 \%$ higher than $\mathrm{TiO}_{2}$, where $\mathrm{Cu}$ showed the lowest heat transfer rate with $4 \%$ compared to the $\mathrm{Al}_{2} \mathrm{O}_{3}$-water nanofluid. It is worth noting that all of the Rayleigh numbers tested in the present study were in laminar flow, since turbulent flows are in the range of $>10^{8}$.

The results clearly indicate that heat transfer is less sensitive to the nanoparticle type compared to the Rayleigh number effect. As shown in Figs. 3 and 4, an increase in the Rayleigh number lead to an increase in the heat transfer rate. This increase in heat transfer is due to the sensitivity of the boundary layer thickness to the higher Rayleigh number, where for lower Rayleigh numbers the boundary layer thickness is insensitive to the Rayleigh number.

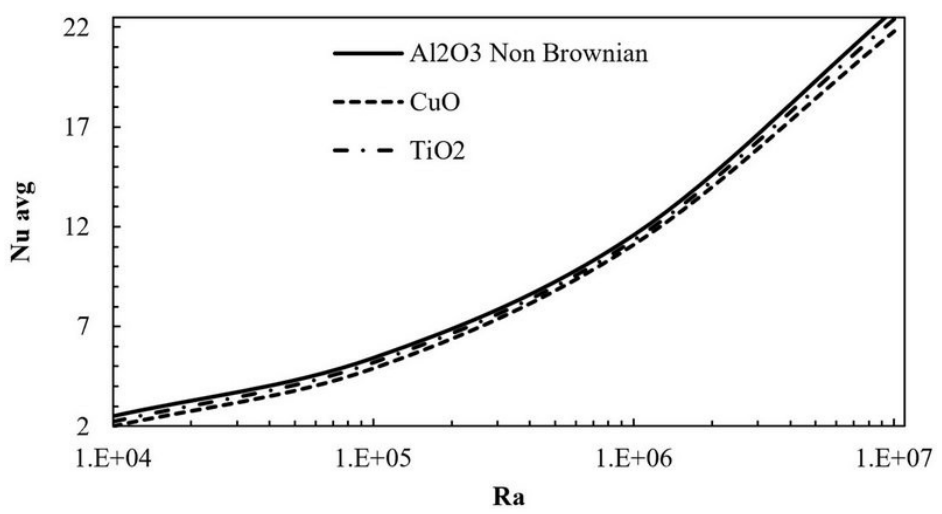

FIG. 4: Effect of nanoparticles on the heat transfer rate 
The effect of the Brownian motion along with the nanoparticle type on the heat transfer for a range of Rayleigh numbers was also investigated and the results are presented in Fig. 5 . The three different nanoparticles $\left(\mathrm{Cu}, \mathrm{TiO}_{2}\right.$, and $\left.\mathrm{Al}_{2} \mathrm{O}_{3}\right)$ were used with water as the nanofluid. The Brownian motion was considered and incorporated through the effective thermal conductivity of the nanofluids tested. The results highlighted that the Nusselt number is enhanced with an increase in the Rayleigh number, and this increase was evident for all nanoparticles tested. However, when considering Brownian motion, variation of the Nusselt number was almost the same for all nanofluids at low Rayleigh numbers, where for Rayleigh number was higher than $1 \times 10^{6}$.

As seen in Fig. 5, at $\mathrm{Ra}=1 \times 10^{7}$ the change in the Nusselt number is up to $4.6 \%$. This increase could be attributed to the high thermal conductivity of the $\mathrm{Al}_{2} \mathrm{O}_{3}$ nanoparticle compared to $\mathrm{TiO}_{2}$ (35 to 8.93), and also to the high specific heat of $\mathrm{Al}_{2} \mathrm{O}_{3}$ compared to $\mathrm{Cu}$ (765 to 385). By comparing the results in Figs. 4 and 5, it is obvious that the Nusselt number is higher when considering Brownian motion; however, the heat transfer enhancement is less sensitive to the nanoparticle type when taking into account the Brownian motion effect.

In natural convection, it is essential to understand the change in velocity. The flow velocity variation was investigated thoroughly for all Rayleigh numbers. The investigations covered four volume fractions for the $\mathrm{Al}_{2} \mathrm{O}_{3}$-water nanofluid $(\varphi=2 \%, 3 \%, 4 \%$, and $6 \%)$. The results are shown in Figs. 6-9.

The distribution of the vertical velocity component with the normalized distance $x / L$ for Ra $=1 \times 10^{4}$ is plotted in Fig. 6 . The trend is consistent with the expected behavior of the natural convection phenomenon in an enclosure. The origin in the graph represents the middle of the hot wall, which is located on the left of the square enclosure. The middle of the cold wall is located at a normalized distance equal to 1 . The flow accelerates from the hot wall to the cold wall due to the buoyance forces, which are the main influence of the natural convection. This buoyance force results from the temperature difference between the hot and cold walls. The volume fraction of $2 \%$ showed the highest velocity among the other volume fractions tested. It can be clearly seen that the increase in the volume fraction decreased the vertical velocity component. This finding is explained by the deterioration of the heat transfer due to the increase in the volume fraction, since the increase in the velocity in the thermal boundary layer region is accompanied by an increase in the heat transfer rate.

This was further investigated for other Rayleigh numbers. Figure 7 illustrates the variation of the vertical velocity component with volume fractions of $2 \%, 3 \%, 4 \%$, and $6 \%$ for $\mathrm{Ra}=$

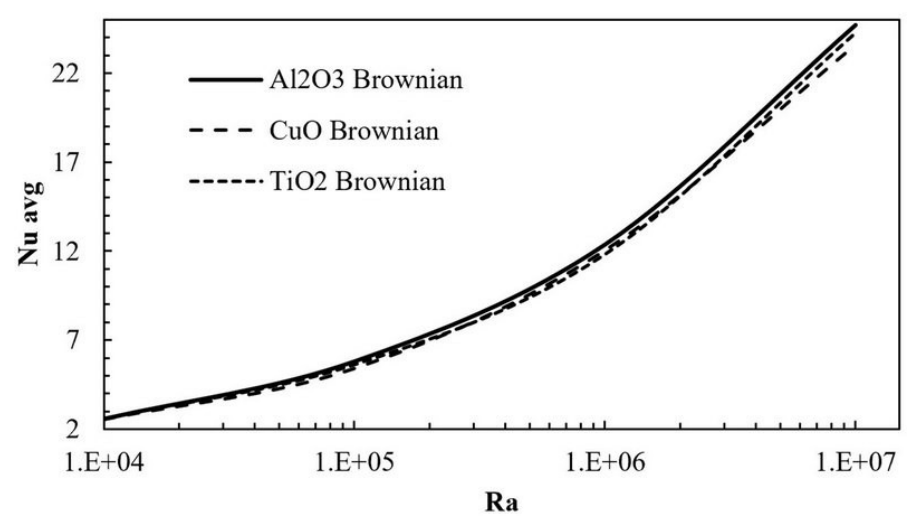

FIG. 5: Effect of Brownian motion and nanoparticles on the Nusselt number 


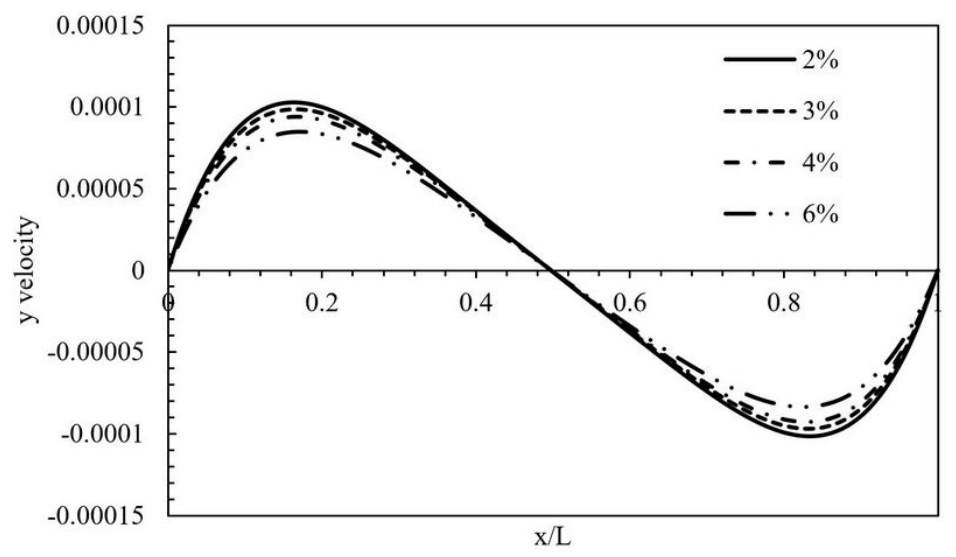

FIG. 6: Velocity variation for $\mathrm{Ra}=1 \times 10^{4}$

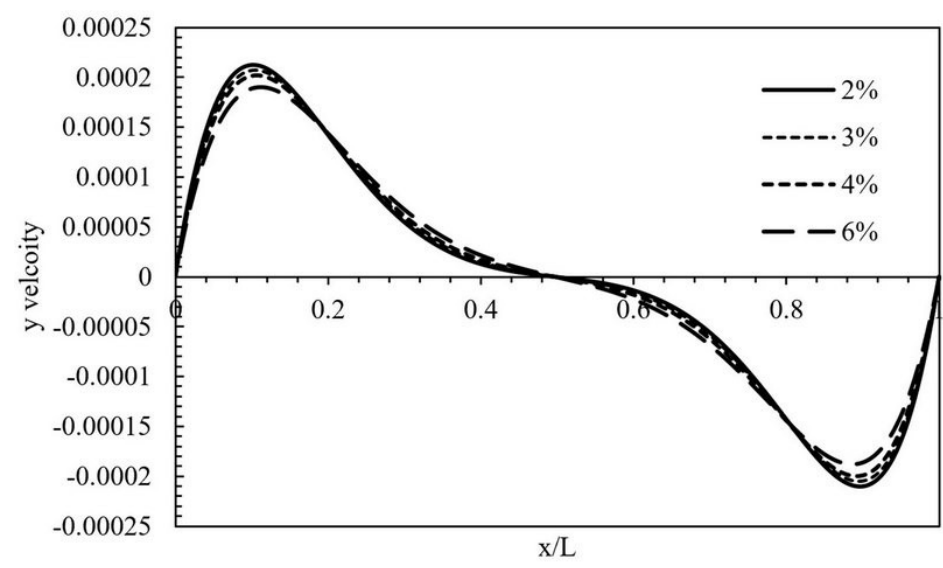

FIG. 7: Velocity variations with the volume fraction for $\mathrm{Ra}=1 \times 10^{5}$

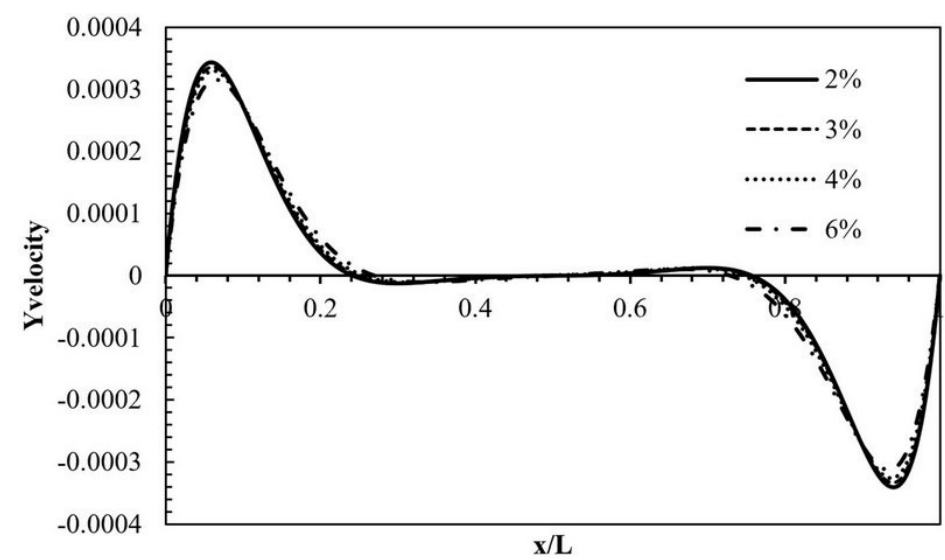

FIG. 8: Variation of the velocity with the volume fraction for $\mathrm{Ra}=1 \times 10^{6}$ 


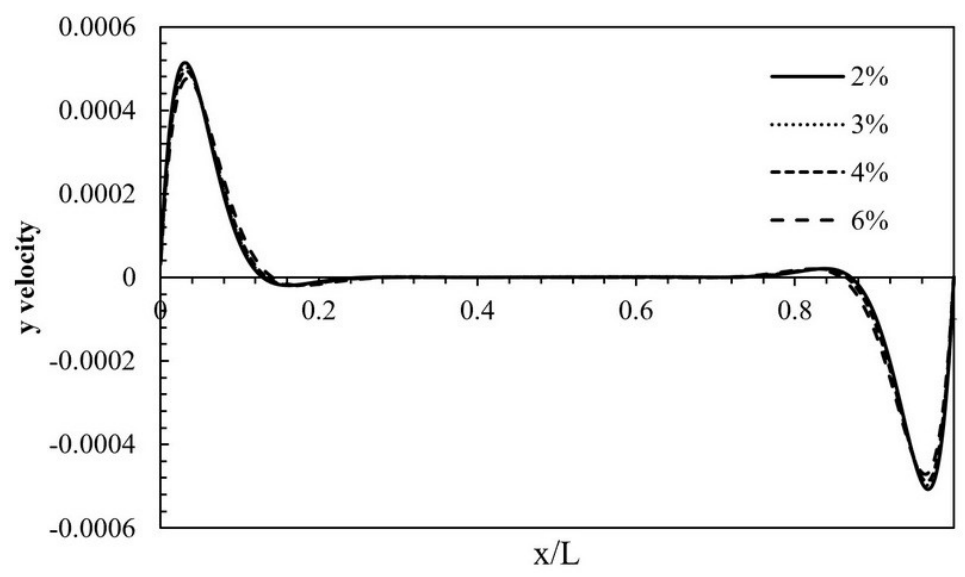

FIG. 9: Velocity variation with the volume fraction for $\mathrm{Ra}=1 \times 10^{7}$

$1 \times 10^{5}$. The velocity profile as depicted in Fig. 7 was found to decrease with an increase

in the volume fraction. This has a negative impact on the heat transfer performance since the effective viscosity is more pronounced in natural convection, as seen in Eq. (13), where viscosity is increased with an increase in the volume fraction. Despite the increase in thermal conductivity, which promotes heat transfer, the augmentation in viscosity is significant, and hence, the Nusselt number is affected by the increase in the viscosity.

A similar finding is reported in Figs. 8 and 9. The vertical velocity component shows a parabolic variation near the isothermal wall due to the buoyant flow inside the enclosure. It was also found that the vertical velocity profile is insensitive to the nanoparticle type, since the three nanofluids tested showed a similar vertical velocity component profile. This was attributed to the influence of the volume fraction on the effective viscosity, where the nanoparticle effect had no influence on it. Although the higher volume fraction showed less velocity on the hot wall, its corresponding velocity on the cold wall was higher. This change in flow field was directly affected by particle suspension; however, the flow velocity in the cavity canter was almost zero. This vertical velocity component profile helps in understanding the direction of the flow rotation.

It should also be noted that as the Rayleigh number increased, the velocity increased. The results in Fig. 10 show clearly this velocity change. The volume fraction used in the graph is $2 \%$, and the Brownian effect was considered in this case. From the graph, it can be seen that the convection term is more pronounced at higher Rayleigh numbers in the isotherm walls, i.e., in the near-wall region where the velocity is almost zero at the normalized distance in the enclosure in the range $0.2-0.8$.

The change in the velocity for various Rayleigh numbers tested in the present investigation can lead to a better understanding of the enhancement of the heat transfer due to Rayleigh growth, since the velocity is more pronounced in the viscous layer at the higher Rayleigh number; therefore, the effect of an increase in viscosity increase becomes less and subsequently heat transfer is promoted. On the other hand, the effect of the volume fraction on the heat transfer rate was negative; therefore, the heat transfer rate deteriorated with an increase in the volume fraction as reported by many previous works in the literature. However, with no solid explanations for this influence, some researchers have attributed this to the strong effect of the viscosity in natural convection, where the viscosity increases with an increase in the volume fraction. As can 


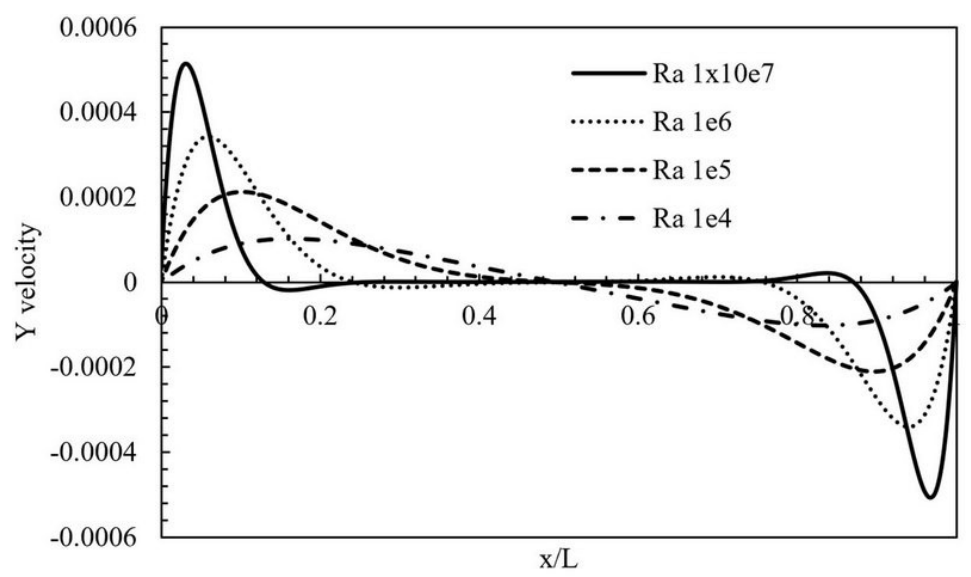

FIG. 10: Velocity change with the Rayleigh number

be seen by Eq. (13), this augmentation in viscosity is accompanied with an increase in thermal conductivity due to the increase in the volume fraction.

The shear stress effect was also investigated in this study. In order to gain understanding of this effect, the velocity gradients $d_{u} / d_{x}$ and $d_{v} / d_{y}$ were studied for different Rayleigh numbers. The effect of the volume fraction was also investigated. The results are presented in Figs. 1113 for $\mathrm{Ra}=1 \times 10^{4}, 1 \times 10^{6}$, and $1 \times 10^{7}$, respectively. The simulations were devoted to the $\mathrm{Al}_{2} \mathrm{O}_{3}$-water nanofluid only since the nanoparticle type effect on the velocity was neglected as discussed previously. The axial velocity gradient is zero at the hot and cold walls and its maximum value is located at the center of the enclosure. This implies that the axial velocity is zero at the isothermal wall. As noted in Fig. 11, the velocity gradient increases with a decrease in the volume fraction. This is explained by the increase in the viscous effect due to the particle suspension. This variation applies to all Rayleigh numbers tested. However, it was also noted that an increase in the Rayleigh number led to a decrease in the axial velocity gradient at constant volume fraction. Another interesting finding, represented by the variation of the axial velocity

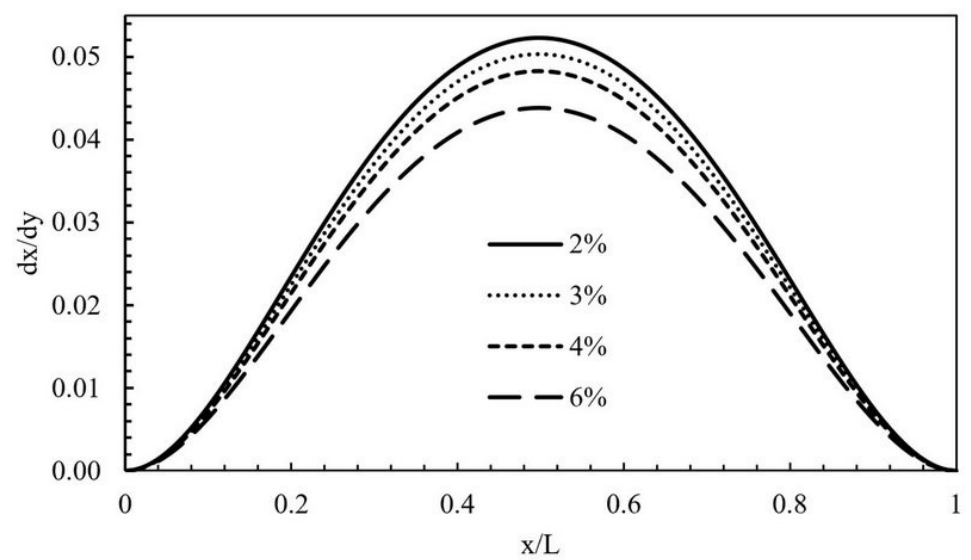

FIG. 11: Variation of the velocity gradient with the volume fraction for $\mathrm{Ra}=1 \times 10^{4}$ 


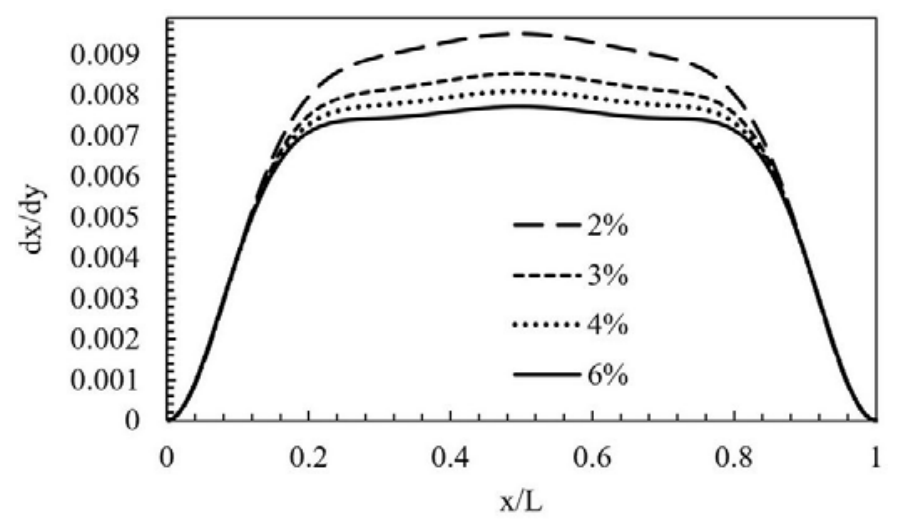

FIG. 12: Variation of the velocity gradient with the volume fraction for $\mathrm{Ra}=1 \times 10^{6}$

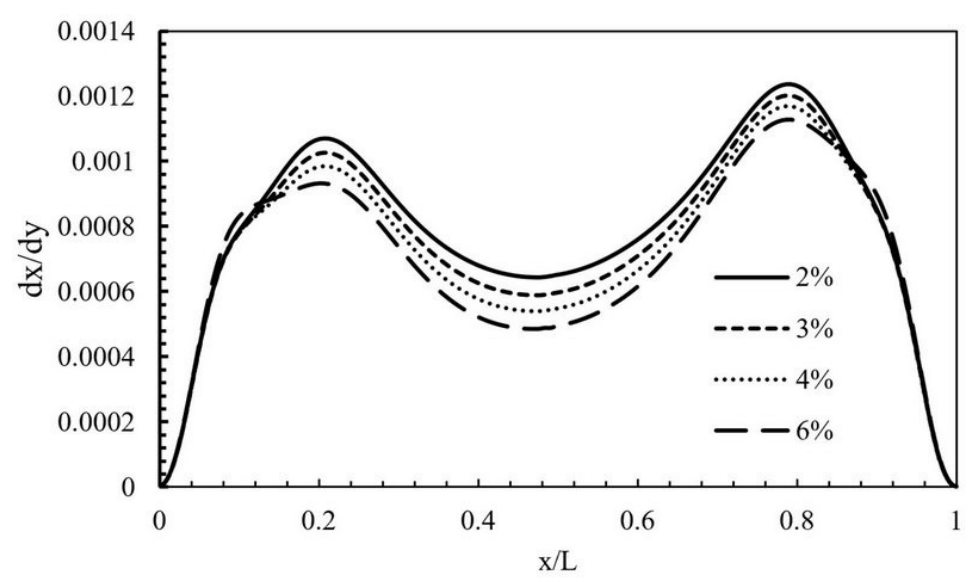

FIG. 13: Variation of the velocity gradient with the volume fraction for $\mathrm{Ra}=1 \times 10^{7}$

gradient in the middle of the enclosure, was that as the Rayleigh number increased the peak of the parabola gradually went down in relation to the growth of the Rayleigh number. At Ra $=1 \times$ $10^{7}$, two peak values were noticed for the axial velocity gradient. These two values are explained by the large change in the velocity in the middle of the enclosure.

It is also worth mentioning that the effect of the volume fraction is more pronounced at the center of the enclosure, where at the isothermal walls the axial velocity gradient is insensitive to the volume fraction. This is attributed to the sharp fall of the velocity in the near-wall region. Figures 14-17 illustrate the change in the velocity gradient for the vertical component at the center line of the enclosure for a range of volume fractions at Ra $=1 \times 10^{4}, 1 \times 10^{5}, 1 \times$ $10^{4}, 1 \times 10^{6}$, and $1 \times 10^{7}$, respectively. It was found that the velocity gradient increased with an increase in the volume fraction at the isotherm walls (hot and cold) and decreased with an increase in the volume fraction in the middle of the enclosure. This agrees well with the previous finding that the velocity has a minimum value at this location.

The vertical velocity gradient has a maximum value at the isothermal walls. The explanation for this is that, when taking shear stress Eq. (20), the maximum shear stress is located at the 


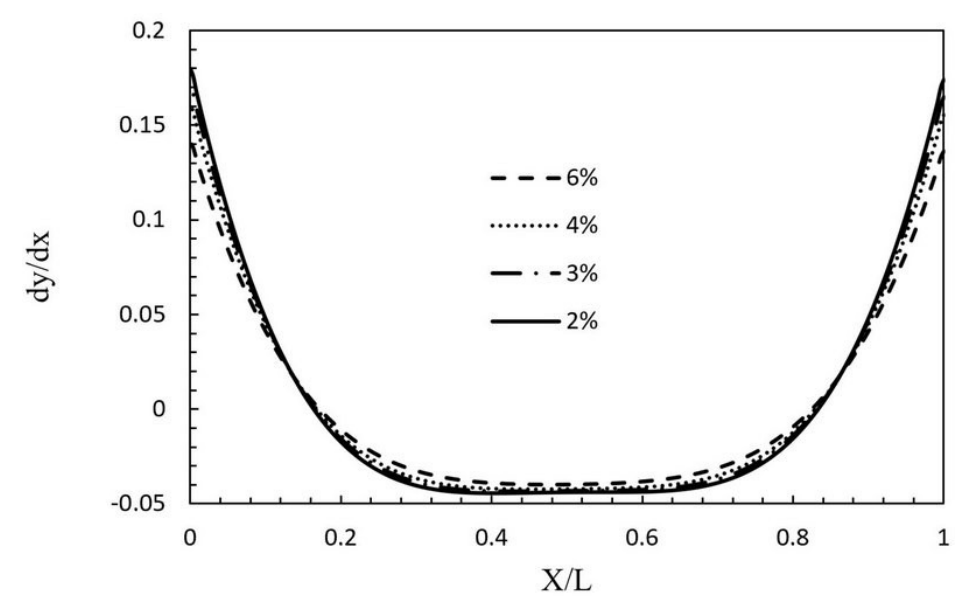

FIG. 14: Velocity gradient variation with the volume fraction for $\mathrm{Ra}=1 \times 10^{4}$

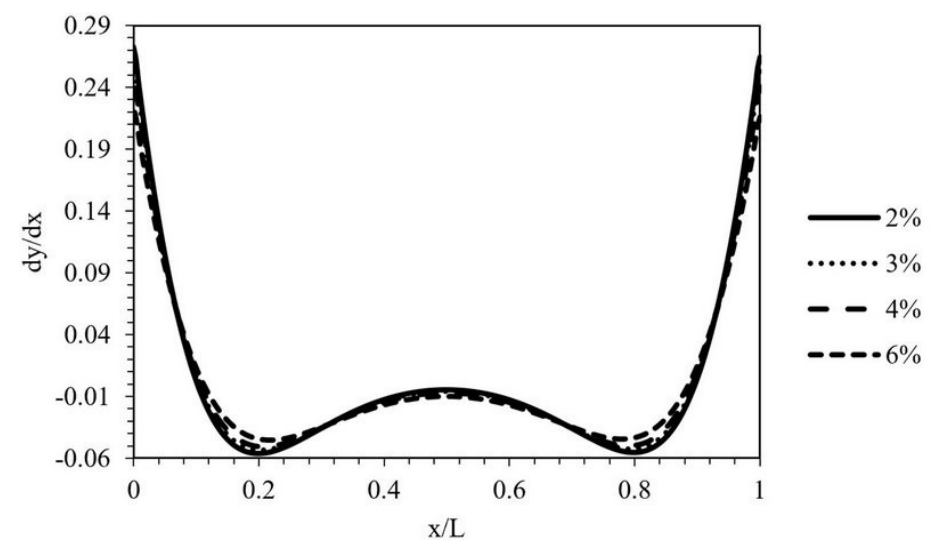

FIG. 15: Variation of the velocity gradient with the volume fraction for $\mathrm{Ra}=1 \times 10^{5}$

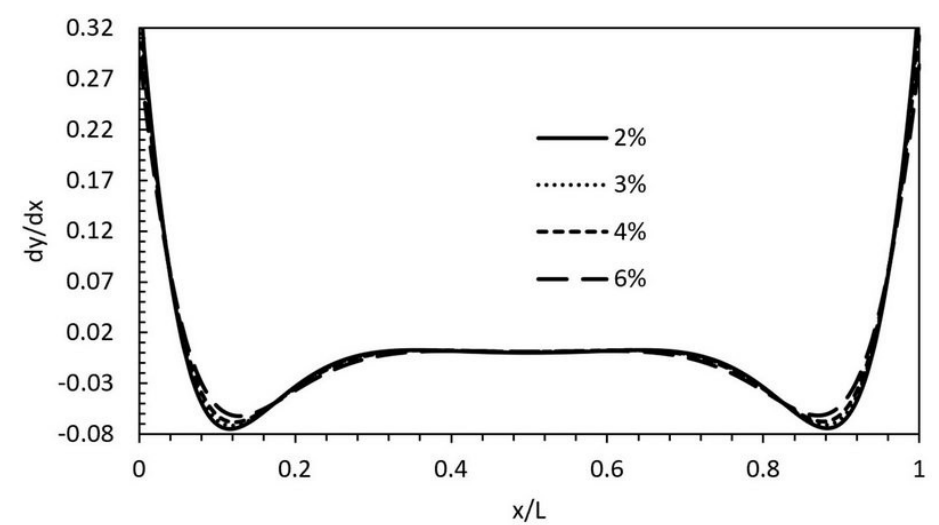

FIG. 16: Variation of the velocity gradient with the volume fraction for $\mathrm{Ra}=1 \times 10^{6}$ 


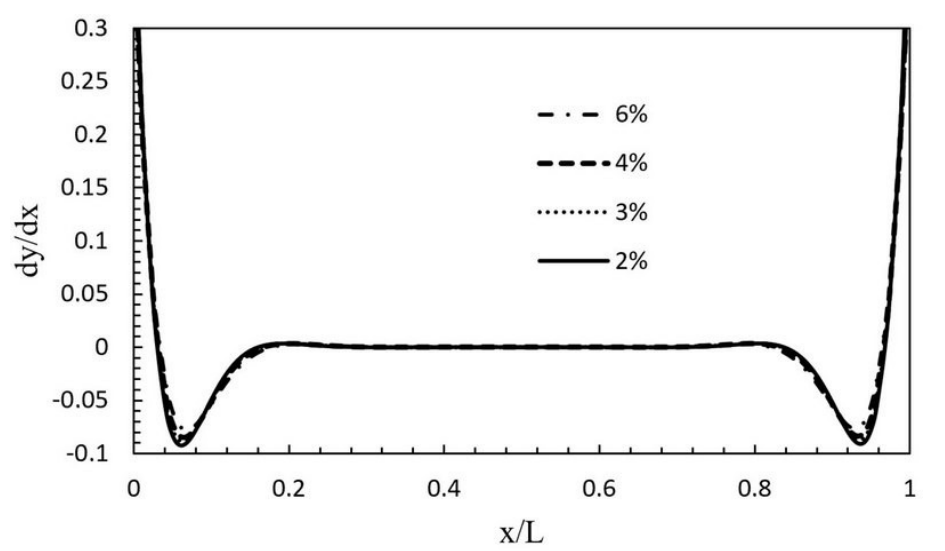

FIG. 17: Variation of the velocity gradient with the volume fraction for $\mathrm{Ra}=1 \times 10^{7}$

walls. As a result, at the thin fluid layer the velocity gradient and shear stress are large, while at the boundary layer both the shear stress and the velocity gradient are negligible

$$
\mathrm{T}=\mu \frac{d v}{d x}
$$

As the Rayleigh number rises, the vertical velocity component becomes less sensitive to the volume fraction of the particles. In which case, the convection effect is more prominent where the viscous effect has declined considerably.

In order to understand the relation between the velocity gradient and the Rayleigh number, Fig. 18 is introduced, which depicts the variation of different Rayleigh numbers at the middle line of the enclosure with the velocity gradient at a constant volume fraction $(\varphi=2 \%)$. It is clearly seen that as the Rayleigh number increases, the velocity gradient increases in the near-wall region, where shear stress has the maximum value. However, when the boundary layer increases, the velocity gradient decreases with the increase in the Rayleigh number; particularly, in the normalized distance ranges $(0.056-0.196)$ and $(0.844-0.984)$. This opposite effect is attributed to

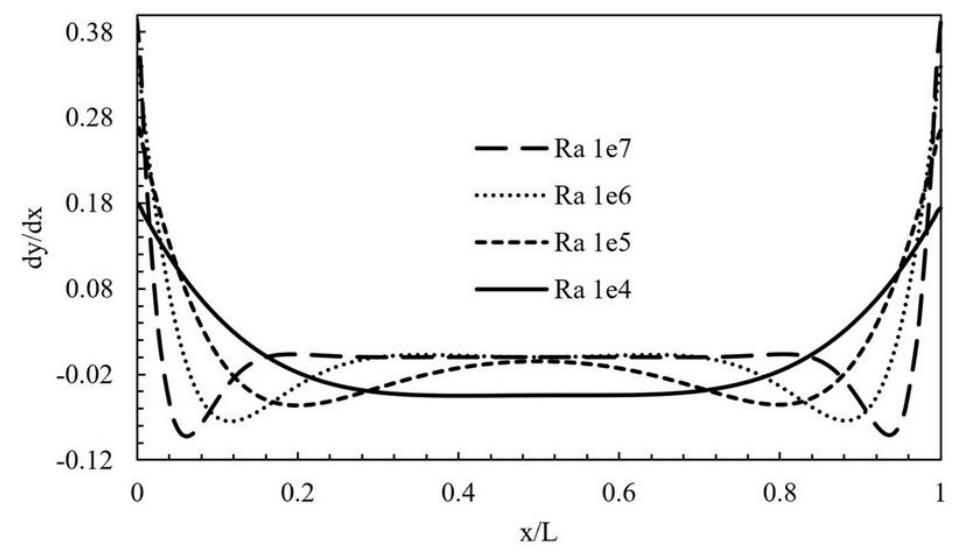

FIG. 18: Rayleigh number change with the velocity gradient 
a decline in the viscous effect with the growth in the boundary layer thickness. With increasing distance from the isothermal walls, the viscosity effect gradually vanishes to the location where the velocity gradient again promotes the Rayleigh enhancement. This augmentation is explained by the dominant buoyant forces over the viscous forces in the circulation inside the enclosure.

In order to gain better understanding of the flow circulation and how the heat performance is affected, the contours of the temperature are presented for $\mathrm{Ra}=1 \times 10^{4}, 1 \times 10^{5}, 1 \times 10^{6}$, and $1 \times 10^{7}$ in Figs. 19(a)-19(d), respectively. It is well established that due to the buoyancy effect and the gravitational force the flow moves in the enclosure from the hot wall to the cold wall. This motion can be visibly seen in the different Rayleigh contours. However, it was noted that with the increase in the Rayleigh number the flow steeply advanced, which was improved by the increase in the vertical velocity component as discussed previously. This rise is accompained with heat transfer enhancement.

\section{CONCLUSIONS}

The natural convection problem with Brownian motion utilizing various nanofluids was investigated and the results were presented and discussed. Four Rayleigh numbers were tested in the present study $\left(\mathrm{Ra}=1 \times 10^{4}, 1 \times 10^{5}, 1 \times 10^{6}\right.$, and $\left.1 \times 10^{7}\right)$, as well as a range of volume

a

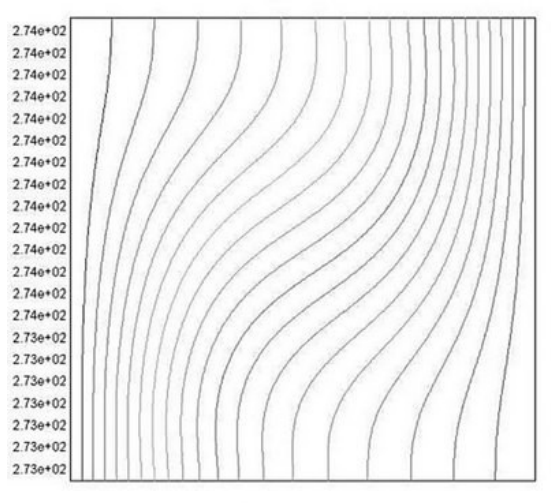

C

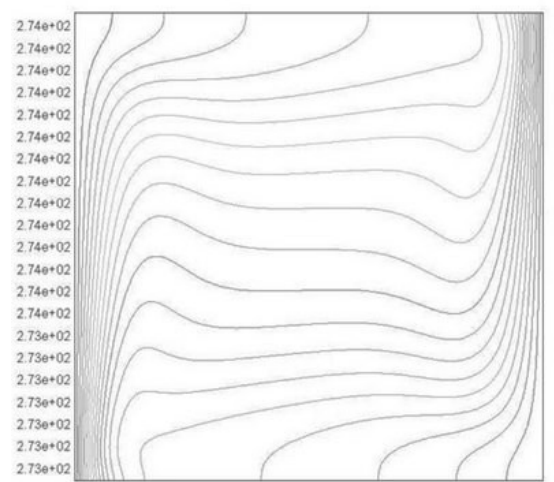

$\mathrm{b}$

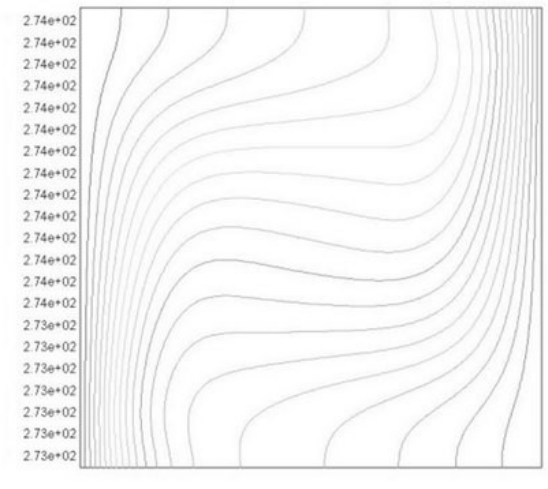

d

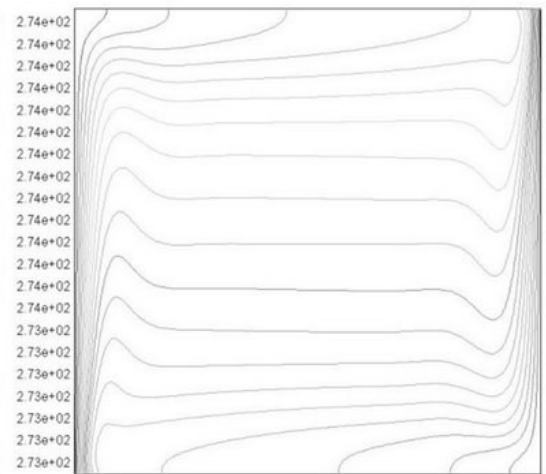

FIG. 19: Isotherm contours for $\mathrm{Ra}=1 \times 10^{4}$ (a), $\mathrm{Ra}=1 \times 10^{5}$ (b), $\mathrm{Ra}=1 \times 10^{6}$ (c), and $\mathrm{Ra}=1 \times 10^{7}$ (d) 
fractions from $2 \%$ to $6 \%$. The heat transfer deteriorated with an increase in the volume fraction of the nanoparticle, and this applied to all of the nanoparticles tested. The heat transfer improved with an increase in the Rayleigh number. The effect of Brownian motion was also investigated and the results showed that the Brownian motion effects were pronounced at the higher Rayleigh numbers; however, the heat transfer with Brownian motion showed an improvement compared to when the Brownian motion was neglected. The velocity gradients were studied and the results showed that the velocity gradient was influenced by the volume fraction of the nanoparticles. The various nanoparticles tested in the present study showed similar heat transfer performance behavior. However, this effect was clearly seen compared to the case in which the Brownian motion effect was not considered, particularly at higher Rayleigh numbers.

\section{REFERENCES}

Aminossadati, S.M. and Ghasemi, B., Natural Convection Cooling of a Localised Heat Source at the Bottom of a Nanofluid-Filled Enclosure, Eur. J. Mech. B/Fluids, vol. 28, no. 5, pp. 630-640, 2009.

ANSYS, Workbench A Release 15, Canonsburg, PA: ANSYS, Inc., 2013.

Choi, S.U.S. and Eastman, J.A., Enhancing Thermal Conductivity of Fluids with Nanoparticles, J. Heat Transf., vol. 121, no. 2, pp. 280-289, 1995.

Corcione, M., Habib, E., and Quintino, A., A Two-Phase Numerical Study of Buoyancy-Driven Convection of Alumina-Water Nanofluids in Differentially-Heated Horizontal Annuli, Int. J. Heat Mass Transf., vol. 65, pp. 327-338, 2013.

Etaig, S., Hasan, R., and Perera, N., Investigation of a New Effective Viscosity Model for Nanofluids, Procedia Eng., vol. 157, pp. 404-413, 2016.

Etaig, S., Hasan, R., and Perera, N., Investigation of the Flow Characteristics of Titanium-Oxide-Water Nanofluid in Microchannel with Circular Cross Section, Am. J. Nano Res. Appl., vol. 5, no. 6, p. 102, 2017.

Etaig, S., Hasan, R., and Perera, N., A New Effective Viscosity Model for Nanofluids, Int. J. Numer. Methods Heat Fluid Flow, vol. 28, no. 3, pp. 571-583, 2018.

Ghasemi, B. and Aminossadati, S.M., Natural Convection Heat Transfer in an Inclined Enclosure Filled with a Water-CuO Nanofluid, Numer. Heat Transf., Part A: Appl., vol. 55, no. 8, pp. 807-823, 2009.

Ghasemi, B. and Aminossadati, S.M., Brownian Motion of Nanoparticles in a Triangular Enclosure with Natural Convection, Int. J. Thermal Sci., vol. 49, no. 6, pp. 931-940, 2010.

Ho, C.J., Liu, W.K., Chang, Y.S., and Lin, C.C., Natural Convection Heat Transfer of Alumina-Water Nanofluid in Vertical Square Enclosures: An Experimental Study, Int. J. Thermal Sci., vol. 49, no. 8, pp. 1345-1353, 2010.

Kahveci, K. and Öztuna, S., MHD Natural Convection Flow and Heat Transfer in a Laterally Heated Partitioned Enclosure, Eur. J. Mech. B/Fluids, vol. 28, no. 6, pp. 744-752, 2009.

Khanafer, K., Vafai, K., and Lightstone, M., Buoyancy-Driven Heat Transfer Enhancement in a TwoDimensional Enclosure Utilizing Nanofluids, Int. J. Heat Mass Transf., vol. 46, no. 19, pp. 3639-3653, 2003.

Koo, J. and Kleinstreuer, C., A New Thermal Conductivity Model for Nanofluids, J. Nanopart. Res., vol. 6, no. 6, pp. 577-588, 2004.

Manca, O., Musto, M., and Naso, V., Natural Convection on a Vertical Isoflux Plate with a Downstream Unheated Extension and a Parallel Shroud, in Proc. of ASME-IMECE, pp. 103-112, 2001.

Nasrin, R., Alim, M.A., and Chamkha, A.J., Buoyancy-Driven Heat Transfer of Water- $\mathrm{Al}_{2} \mathrm{O}_{3}$ Nanofluid in a Closed Chamber: Effects of Solid Volume Fraction, Prandtl Number and Aspect Ratio, Int. J. Heat Mass Transf., vol. 55, nos. 25-26, pp. 7355-7365, 2012. 
Oztop, H.F. and Abu-Nada, E., Numerical Study of Natural Convection in Partially Heated Rectangular Enclosures Filled with Nanofluids, Int. J. Heat Fluid Flow, vol. 29, no. 5, pp. 1326-1336, 2008.

Putra, N., Roetzel, W., and Das, S., Natural Convection of Nano-Fluids, Heat Mass Transf., vol. 39, nos. 8-9, pp. 775-784, 2003.

Saleh, H., Roslan, R., and Hashim, I., Natural Convection Heat Transfer in a Nanofluid-Filled Trapezoidal Enclosure, Int. J. Heat Mass Transf., vol. 54, nos. 1-3, pp. 194-201, 2011.

Sarris, I.E., Lekakis, I., and Vlachos, N.S., Natural Convection in Rectangular Tanks Heated Locally from Below, Int. J. Heat Mass Transf., vol. 47, nos. 14-16, pp. 3549-3563, 2004.

Sun, Q. and Pop, I., Free Convection in a Triangle Cavity Filled with a Porous Medium Saturated with Nanofluids with Flush Mounted Heater on the Wall, Int. J. Thermal Sci., vol. 50, no. 11, pp. 2141-2153, 2011.

Xuan, Y. and Li, Q., Heat Transfer Enhancement of Nanofluids, Int. J. Heat Fluid Flow, vol. 21, pp. 58-64, 2000. 